\title{
High infiltration of mast cells positive to tryptase predicts worse outcome following resection of colorectal liver metastases
}

Shinsuke Suzuki ${ }^{1,2}$, Yasushi Ichikawa ${ }^{3}$, Kazuya Nakagawa' ${ }^{1}$ Takafumi Kumamoto ${ }^{1}$, Ryutaro Mori ${ }^{1}$, Ryusei Matsuyama ${ }^{1}$, Kazuhisa Takeda ${ }^{1}$, Mitsuyoshi Ota ${ }^{4}$, Kuniya Tanaka ${ }^{5}$, Tomohiko Tamura ${ }^{2}$ and Itaru Endo ${ }^{\text {1* }}$

\begin{abstract}
Background: Accumulation of tumor-infiltrating mast cells (MCs) predicts poor survival in several cancers after resection. However, its effect on the prognosis of patients with colorectal liver metastases (CRLM) is not known.

Methods: Our retrospective study included 135 patients who underwent potentially curative resection for CRLM between 2001 and 2010. Expression of tryptase, MAC387, CD83, and CD31, which are markers for MCs, macrophages, mature dendritic cells, and vascular endothelial cells, respectively, was determined via immunohistochemistry of resected tumor specimens. The relationship between immune cell infiltration and long-term outcome was investigated.
\end{abstract}

Results: The median follow-up time was 48.4 months for all patients and 57.5 months for survivors. Overall survival (OS) rates at 1, 3, and 5 years were $91.0,62.4$, and $37.4 \%$, respectively. Five-year disease-free survival (DFS) and OS rates were 21.6 and $38.1 \%$, respectively, in patients with high MC infiltration, and 42.6 and $55.6 \%$, respectively, in patients with low MC infiltration ( $p<0.01$ for both DFS and OS). Infiltration of other types of immune cells did not correlate with survival. Multivariate analyses indicated that hypoalbuminemia and high peritumoral MC infiltration were significant predictors of unfavorable OS.

Conclusion: High peritumoral MC infiltration predicts poor prognosis in patients who underwent hepatectomy for CRLM. The number of MCs in metastatic lesions is important for predicting the prognosis of CRLM patients and as an indication of therapy.

Keywords: Mast cells, Colorectal cancer, Metastasis, Survival

\section{Background}

More than 1 million people are diagnosed with colorectal cancer (CRC) and approximately 0.5 million people die from this disease each year worldwide [1]. CRC is the second most common cancer in women and the third most common cancer in men [2]. Advanced CRC is frequently accompanied by synchronous or metachronous liver metastases [3]. Despite improvements in surgical techniques and the introduction of new chemotherapy agents, overall survival remains poor for most

\footnotetext{
* Correspondence: endoit@yokohama-cu.ac.jp

'Department of Gastroenterological Surgery, Yokohama City University Graduate School of Medicine, 3-9 Fukuura, Kanazawa-ku, Yokohama 236-0004, Japan

Full list of author information is available at the end of the article
}

patients with colorectal liver metastases (CRLM) [4]. Five-year survival rates after hepatectomy are reported to range from 33 to $61 \%$ [5-8].

Different types of infiltrating immune cells [mast cells, (MCs), macrophages (M $\varphi s)$, dendritic cells (DCs), neutrophils, and lymphocytes] surround tumors in variable numbers and have different effects on tumor progression [9]. We reported the significance of tumor-infiltrating lymphocytes, such as regulatory $\mathrm{T}$ cells, as a predictor of worse outcome in CRLM patients [10]. Tumor-infiltrating MCs (TIMs) are considered a primary host immune response against cancer. However, their function varies among different cancers [11-17]. The function of TIMs near CRLM has never been reported. 
Many tumors secrete stem cell factor (SCF), which attracts MCs to tumor sites [18]. Activation of the c-Kit pathway leads to $\mathrm{MC}$ activation and consequent expression of angiogenic cytokines [e.g., vascular endothelial growth factor (VEGF), platelet-derived growth factor (PDGF), and fibroblast growth factor 2 (FGF-2)] and tryptase-mediated MC degranulation [19, 20]. Tryptase is an agonist of protease-activated receptor-2 (PAR-2), expressed on vascular endothelial cells [21]. Activation of PAR-2 induces cell proliferation and release of interleukin 6 (IL-6) and granulocyte-macrophage colony stimulating factor, act as angiogenic molecules [22]. Therefore a strong positive correlation between MC density and microvascular density in many human and animal malignancies [23-34].

MCs are classically and conventionally identified via histochemical methods. Toluidine blue (Undritz stain) metachromatically stains MC granules red or blue-red owing to the presence of sulfated proteoglycans (e.g., heparin) [35]. MCs can be immunohistochemically stained with antibodies to c-Kit or proteins in their granules, such as tryptase or chymase. Primary anti-chymase and anti-tryptase antibodies produce diffuse cytoplasmic staining. Tryptase activates protease-activated receptor-2, and it's activity stimulates proliferation of colon cancer cells [36]. Although TIMs may be a useful prognostic marker in CRC, their significance in CRLM is unclear. Therefore, the aim of the present study was to determine the prognostic significance of $\mathrm{MC}$ density in patients with CRLM.

\section{Methods}

\section{Patients}

Between January 2001 and December 2010, 258 patients with CRLM underwent initial liver resection at the Department of Gastroenterological Surgery at Yokohama City University Graduate School of Medicine. Patients who could not undergo curative resection $(n=61)$ or died during the immediate postoperative period (30 days) $(n=1)$ were excluded from our retrospective study. Patients with a pathologically complete response to neoadjuvant chemotherapy (NAC) $(n=4)$ were also excluded because evaluation of the initial cancer site in the liver was impossible. Of the remaining 192 patients, 135 with both clinicopathological data and resected specimens were analyzed. Primary lesion tissues were collected for 69 of the 135 patients. Preoperative staging, preoperative chemotherapy, hepatectomy procedures, adjuvant chemotherapy, and patient follow-up were previously described [37, 38]. 40 patients received oxaliplatin, and 17 patients received bevacizumab. The end of follow-up was defined as the time of the last follow-up (August 2014) or death. Informed consent for participation in the study was obtained from participants. Our study was approved by the Yokohama City University ethics committee.

\section{Immunohistochemistry}

Tissue sections ( $4 \mu \mathrm{m}$ thick) were deparaffinized in $\mathrm{xy}$ lene and rehydrated through a series of graded alcohol. The endogenous peroxidase activity of the specimens

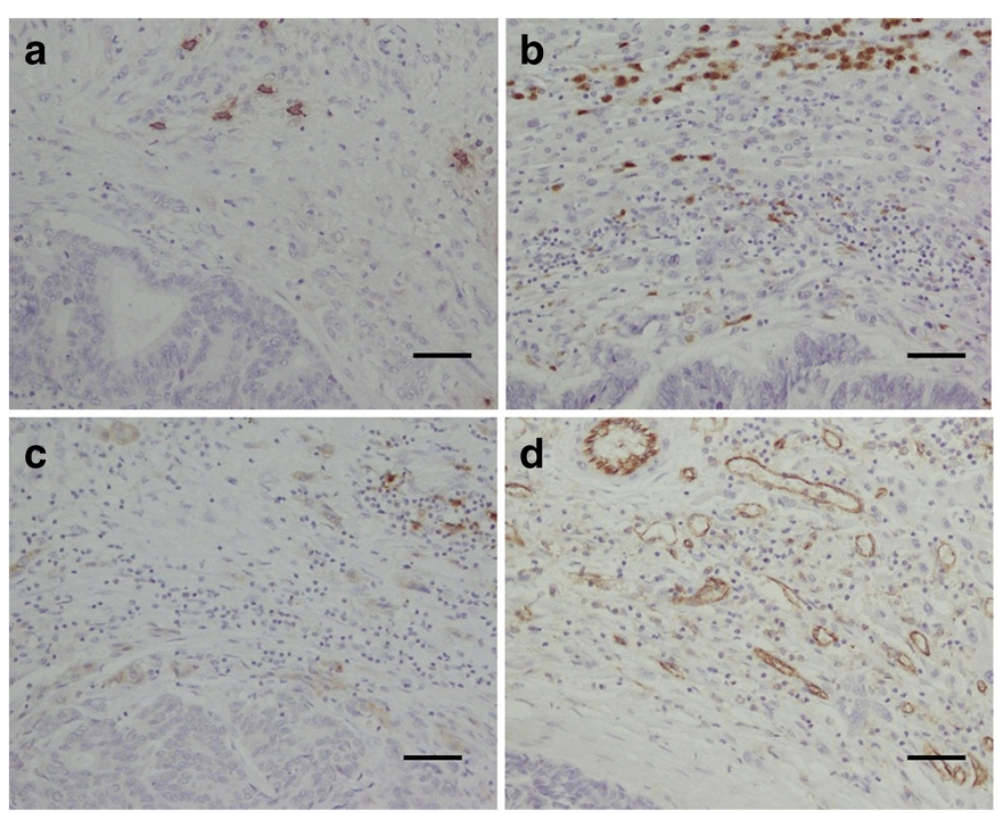

Fig. 1 Representative immunohistochemical staining patterns of formalin-fixed, paraffin-embedded sections of colorectal liver metastases using monoclonal antibodies to (a) tryptase, (b) MAC387, (c) CD83, and (d) CD31. Original magnification, ×200. Scale bar, $50 \mu \mathrm{m}$ 
was blocked by incubating the slides in absolute methanol containing $0.3 \%$ hydrogen peroxide for $30 \mathrm{~min}$ at room temperature. Antigen retrieval was carried out via autoclave pretreatment $\left(120^{\circ} \mathrm{C}\right.$ for $\left.5 \mathrm{~min}\right)$ in citrate buffer ( $\mathrm{pH}$ 6). After washing with phosphate-buffered saline, specimens were incubated with $10 \%$ rabbit serum albumin for $10 \mathrm{~min}$ and primary antibody at $37^{\circ} \mathrm{C}$ for $1 \mathrm{~h}$.

Mouse monoclonal antibodies were used to recognize tryptase (Abcam AA1, 1:100; MC marker), MAC387
(Abcam MAC387, 1:1000; M $\varphi$ marker), CD83 (Abcam 1H4b, 1:100; mature DC cell marker), and CD31 (Abcam JC 70A, 1:100; vascular endothelial cell marker). Immunohistochemical reactions were visualized using a HistoFine kit (Nichirei Pharmaceutical, Tokyo, Japan) and a DAB kit (Dako, Carpinteria, CA, USA). The sections were counterstained with hematoxylin and examined microscopically (Fig. 1a-d). As the negative control, Mouse IgG1 isotype control (monoclonal mouse

Table 1 Clinicopathological charasteristics of 135 CRLM patients

\begin{tabular}{|c|c|c|c|c|}
\hline \multirow[t]{2}{*}{ Variable } & \multirow[t]{2}{*}{ All cases } & \multicolumn{2}{|c|}{ Peritumoral MCs } & \multirow[t]{2}{*}{$p$ value } \\
\hline & & Low & High & \\
\hline Number of patients & 135 & 62 & 73 & \\
\hline Age, years & $63.4 \pm 10.0$ & $63.4 \pm 10.1$ & $63.5 \pm 10.0$ & 0.99 \\
\hline $\operatorname{Sex}[n(\%)]$ & & & & 0.60 \\
\hline Male & $84(62.2)$ & $37(59.7)$ & $47(64.4)$ & \\
\hline Female & $51(37.8)$ & $25(40.3)$ & $26(35.6)$ & \\
\hline Location of primary tumor [n (\%)] & & & & 0.90 \\
\hline Colon & $89(65.9)$ & $41(66.1)$ & $48(65.8)$ & \\
\hline Rectum & $46(34.1)$ & $21(33.9)$ & $25(34.2)$ & \\
\hline Primary lymph node metastases [n (\%)] & & & & 0.58 \\
\hline Negative & $44(32.6)$ & $22(35.5)$ & $22(30.1)$ & \\
\hline Positive & $91(67.4)$ & $40(64.5)$ & $51(69.9)$ & \\
\hline Timing $[\mathrm{n}(\%)]$ & & & & 0.06 \\
\hline Synchronous & $78(57.8)$ & $30(48.4)$ & $48(65.8)$ & \\
\hline Metachronous & $57(42.2)$ & $32(51.6)$ & $25(34.2)$ & \\
\hline Distribution [n (\%)] & & & & 0.16 \\
\hline Uniloblar & $56(41.5)$ & $30(48.4)$ & $26(35.6)$ & \\
\hline Biloblar & $79(58.5)$ & $32(51.6)$ & $47(64.4)$ & \\
\hline Tumor number & $5.7 \pm 6.1$ & $4.8 \pm 5.6$ & $6.4 \pm 6.4$ & 0.13 \\
\hline Maximum tumor size, mm & $39.2 \pm 24.6$ & $38.3 \pm 23.2$ & $39.9 \pm 25.8$ & 0.70 \\
\hline Extrahepatic metastases [n (\%)] & & & & 0.11 \\
\hline Present & $33(24.4)$ & $11(17.7)$ & $22(30.1)$ & \\
\hline Absent & $102(75.6)$ & $51(82.3)$ & $51(69.9)$ & \\
\hline Preoperative chemotherapy [n (\%)] & & & & 0.30 \\
\hline Yes & $70(51.9)$ & $29(47.5)$ & $41(56.9)$ & \\
\hline No & $65(48.1)$ & $32(52.5)$ & $31(43.1)$ & \\
\hline Prehepatectomy CRP, mg/L & $0.6 \pm 1.3$ & $0.7 \pm 1.5$ & $0.6 \pm 1.2$ & 0.62 \\
\hline Prehepatectomy Alb, g/dL & $4.0 \pm 0.4$ & $4.0 \pm 0.4$ & $4.0 \pm 0.5$ & 0.53 \\
\hline Prehepatectomy CEA, ng/mL & $201.1 \pm 607.1$ & $111.2 \pm 341$ & $277 \pm 758.0$ & 0.10 \\
\hline Peritumoral MCs & $42.2 \pm 36.8$ & $11.2 \pm 5.2$ & $68.4 \pm 31.1$ & $<0.01$ \\
\hline Normal liver areal MCs & $13.6 \pm 9.9$ & $11.4 \pm 8.6$ & $15.5 \pm 10.6$ & 0.02 \\
\hline Peritumoral M $M s$ & $113.2 \pm 105.1$ & $93.4 \pm 99.1$ & $130.0 \pm 107.7$ & 0.04 \\
\hline Peritumoral mature DCs & $7.6 \pm 8.7$ & $8.2 \pm 6.9$ & $7.1 \pm 10.0$ & 0.43 \\
\hline Micro vessel density & $39.6 \pm 24.9$ & $32.0 \pm 16.6$ & $46.0 \pm 28.9$ & $<0.01$ \\
\hline
\end{tabular}

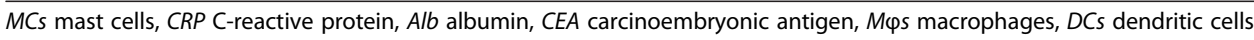


IgG1 clone \#11711; R\&D Systems) was used at the same concentration, then all other steps were followed.

\section{Immunohistochemical evaluation}

Evaluation was performed as previously reported [16, 33, 39, 40]. Cells were counted in each immune cell subset in the 3 most abundant peritumoral areas, and cell numbers were compared. "Peritumoral" was defined as the border between normal liver tissue and the tumor. Therefore we defined peritumoral area as a fields which include tumor three out of ten in view. "Micro vessel density" was defined as the number of blood vessels. Positively stained blood vessels with lumen as well as cell clusters without a lumen and single cells were considered as individual vessels [41]. Cell counting was performed by two investigators (SS and NK) without knowledge of the accompanying clinical information and under the supervision of a pathologist. In cases of discrepancy, a consensus was achieved using a multi-head microscope.

\section{Statistical analysis}

The Kaplan-Meier method was used to estimate Overall survival (OS) and disease-free survival (DFS). To determine the optimal cutoff point, a receiver operating characteristic (ROC) curve was drawn for each variable, and the factor most highly correlated with OS was identified. The threshold was calculated by determining the Youden index [maximum (sensitivity + specificity - 1)] from the ROC curve [42]. Cox regression multivariate models were used to identify independent prognostic factors. The Mann-Whitney U and chi square tests were used to compare cell numbers between subgroups. Statistical significance was defined as $p<0.05$. Analysis was performed using SPSS 20.0 software (SPSS Inc., Chicago, IL, USA).

\section{Results}

\section{Patient characteristics}

The clinicopathological features of patients enrolled in this study are summarized in Table 1 . The patient group included 84 men and 51 women with an age range of 31-83 years (median 63 years). Most patients $(67 \%)$ had primary tumor nodal metastases, $58 \%$ had synchronous liver metastases, and $24 \%$ had extrahepatic disease at the time of hepatectomy. The median number of metastatic nodules was 4 (range 1-32), the median follow-up time was 48.4 months, and the minimum follow-up time was 17.8 months for survivors. DFS rates at 1,3 , and 5 years were 48.1, 32.6, and $20.7 \%$, respectively, for the entire group. OS rates at 1,3 , and 5 years were 91.0, 62.4, and $37.4 \%$, respectively.
Tumor-infiltrating immune cells and clinicopathological features

The distribution of cell numbers for each marker is shown in Table 1 . The average number of TIMs were 84.9 in primary lesion and 42.2 in CRLM. The cutoff points selected using the maximal Youden index were 26 for peritumoral MCs, 176 for peritumoral M $\varphi s, 17$ for peritumoral DCs in CRLM. We found that $54 \%$ (73 of 135) of patients were in the high peritumoral MC group. There was no significant relationship between number of peritumoral MCs and clinicopathological features, with the exception that the number of MCs in normal liver, the number of peritumoral $\mathrm{M} \varphi \mathrm{s}$, and microvessel density were significantly higher in the high peritumoral group than the low peritumoral group ( $p=0.02, p=0.04$, and $p<0.01$, respectively) (Table 1). There was no significant relationship between peritumoral $\mathrm{M} \varphi$ or DC cell counts and clinicopathological features including number of peritumoral vessels (data not shown) or between the number of TIMs in primary lesions and liver metastasis $(r=0.04$, $p=0.73$; Fig. 2). Interestingly, $\mathrm{MC}$ counts were not changed regardless of whether oxaliplatin or bevacizumab is used.

\section{Number of TIMs and survival or recurrence}

The DFS and OS curves for each peritumoral marker in CRLM are shown in Fig. 3. The 5-year DFS and OS rates were 21.6 and $38.1 \%$, respectively, in patients with high peritumoral MC numbers, and 42.6 and $55.6 \%$,

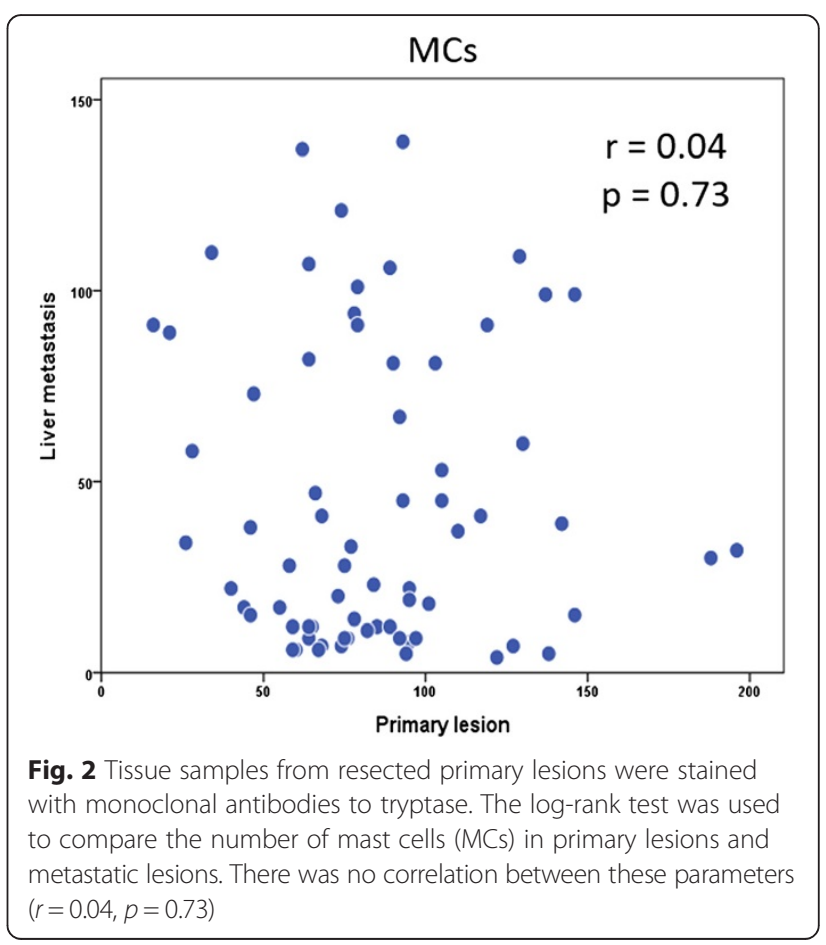




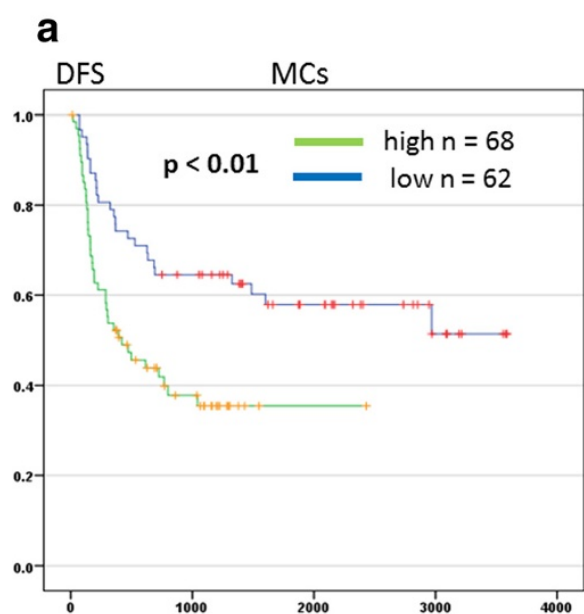

\section{b}

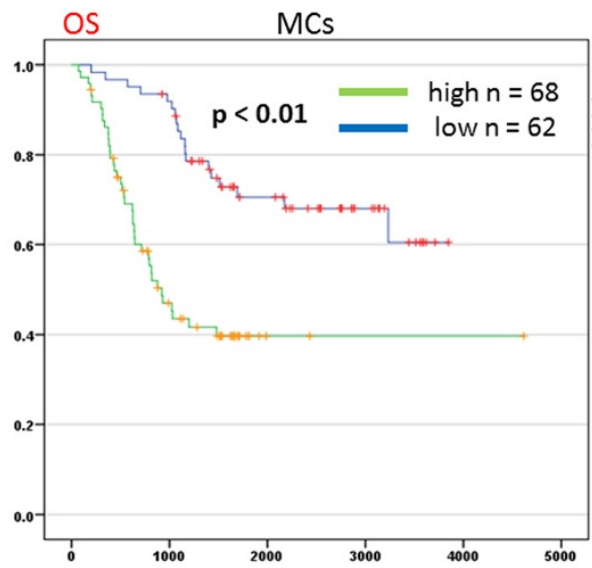

C

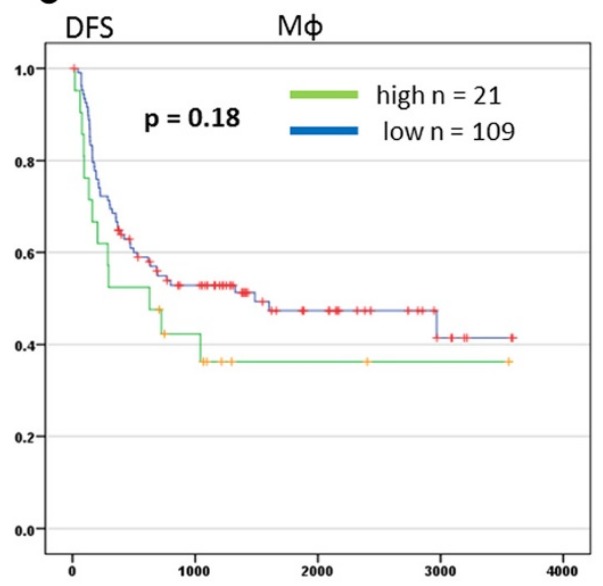

d

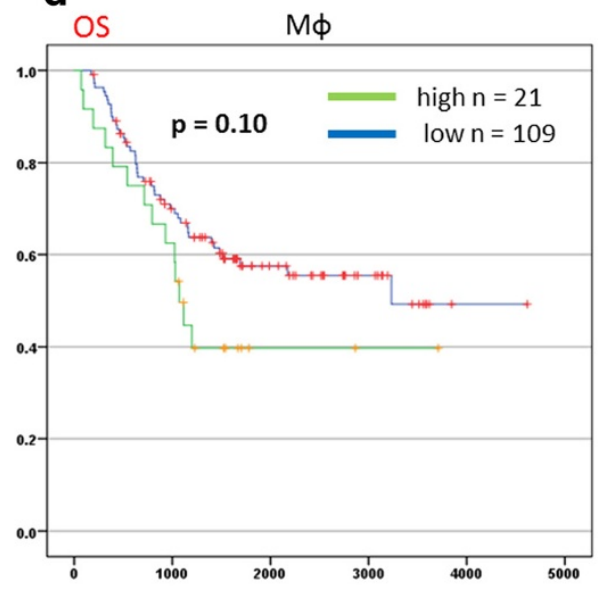

e
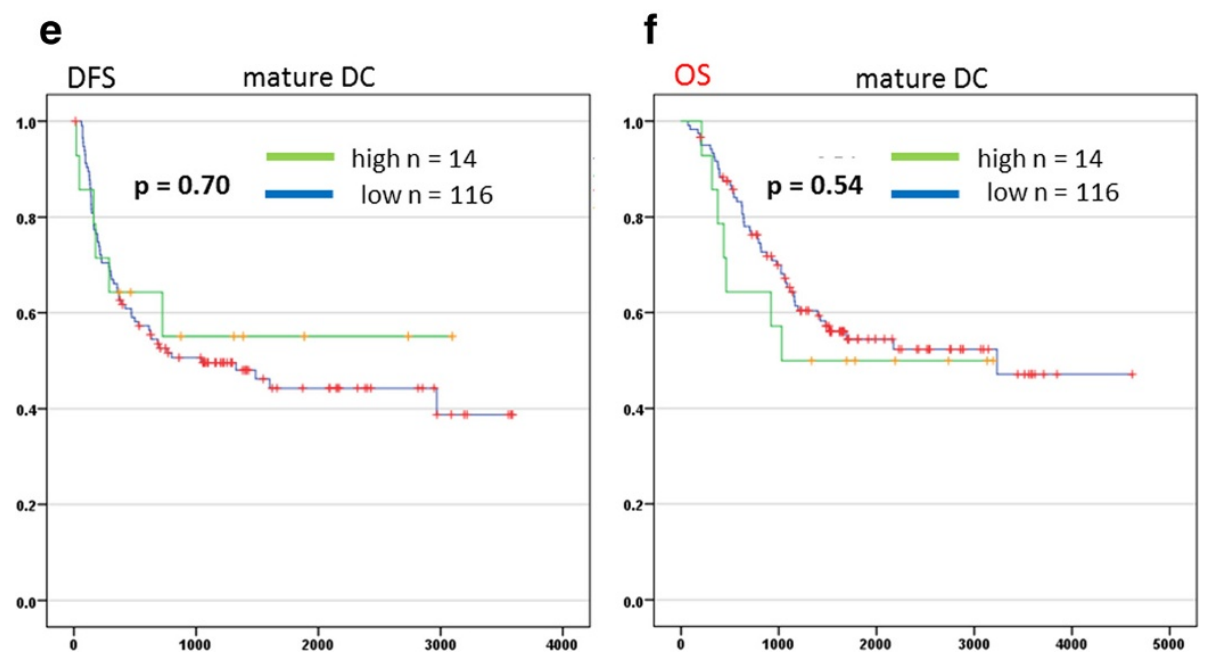

Fig. 3 Tissue samples from resected metastatic lesions were stained with monoclonal antibodies to tryptase, MAC387 and CD83. (a, c, e) Disease-free survival (DFS) and (b, d, f) overall survival (OS) were determined using the Kaplan-Meier method, and the log-rank test was used to compare DFS and OS in groups with low and high numbers of peritumoral mast cells (MCs), peritumoral macrophages (M $\varphi s$ ) and peritumoral mature dendritic cells (DCs) 
respectively, in patients with low MC numbers (Fig. 3a, b). The differences in survival rates between the 2 groups were significant $(p<0.01$ for both DFS and OS). On the other hand, there were no significant differences in DFS and OS between patients with low and high numbers of $\operatorname{M} \varphi s \quad(p=0.18$ and 0.10 , respectively) or mature DCs ( $p=0.70$ and 0.54 , respectively) (Fig. $3 \mathrm{c}-\mathrm{f}$ ).

\section{Prognostic factors}

Fifteen non-immunological and 3 immunological factors were included in the univariate analysis; these did not include treatment-related factors. Nine factors were significantly associated with OS including sex (male), synchronous hepatectomy, distribution of bilobar liver metastases, tumor number, extrahepatic disease, NAC, hypoalbuminemia, high level of pre-hepatectomy carcinoembryonic antigen, and a high peritumoral MC count. The factors with a $\mathrm{p}$ value of $<0.05$ in the univariate analysis were further assessed in a multivariate analysis using a Cox proportional hazards model with stepwise selection. Hypoalbuminemia and high peritumoral MC infiltration were significant predictors of unfavorable OS in the multivariate analysis (Table 2).

\section{Discussion}

We demonstrated an association between the degree of peritumoral $\mathrm{MC}$ infiltration and clinical outcome following resection of CRLM. As shown via multivariate analysis, high peritumoral MC infiltration in CRLM was a significant independent predictor of unfavorable OS. On the other hand, high peritumoral $\mathrm{MC}$ infiltration in primary lesion was not significant independent predictor of unfavorable OS. We suggest that peritumoral MCs induce neo-angiogenesis and tumor cell proliferation. The prognostic significance of TIMs in colorectal cancer has been debated and is controversial [12, 13, 29, 43, 44].

Immunochemical results reflect the type of histological stain used and the area of the specimen analyzed. Because Giemsa and toluidine blue [29] are non-specific, we used anti-tryptase antibody to immunohistochemically detect tryptase-positive MCs. Tryptase activation promotes tumor cell proliferation and neo-angiogenesis by triggering the release of interleukin 6 and granulocytemacrophage colony-stimulating factor from MCs. We thought that tumor-tumor microenvironment interaction could be evaluated by examining the peritumoral area rather than the tumor and therefore focused on this area in this study.

NAC sometimes affects the tumor microenvironment, for example, by causing lymphocyte infiltration as reported by Nakagawa et al. [10]. In our study, there was a significant difference in DFS and OS between patients with low and high MC counts regardless of whether they

Table 2 Univariate and multivariate analyses of overall survival

\begin{tabular}{|c|c|c|c|c|c|c|}
\hline \multirow[t]{2}{*}{ Variable } & \multicolumn{3}{|c|}{ Univariate } & \multicolumn{3}{|c|}{ Multivariate } \\
\hline & $p$ value & Hazard ratio & $95 \% \mathrm{Cl}$ & $p$ value & Hazard ratio & $95 \% \mathrm{Cl}$ \\
\hline Age, $\geqq 70$ years & 0.39 & 0.7 & $0.3-1.6$ & & & \\
\hline Sex, male & 0.02 & 0.4 & $0.2-0.9$ & - & - & - \\
\hline Timing of hepatectomy, synchronous & 0.03 & 2.4 & $1.0-5.0$ & - & - & - \\
\hline Distributution, biloblar & $<0.01$ & 3.4 & $1.5-7.5$ & - & - & - \\
\hline Number of tumors, $\geqq 4$ & $<0.01$ & 4.2 & $1.9-9.4$ & - & - & - \\
\hline Diameter of tumors, $\geqq 3$ & 0.28 & 1.5 & $0.7-3.1$ & & & \\
\hline Primary site, rectum & 0.22 & 1.6 & $0.8-3.4$ & & & \\
\hline Primary lymph node metastases, yes & 0.91 & 1.0 & $0.5-2.3$ & & & \\
\hline Extrahepatic disease, yes & $<0.01$ & 4.5 & $1.9-11$ & - & - & - \\
\hline Neoadjuvant chemotherapy, yes & $<0.01$ & 3.9 & $1.7-8.5$ & - & - & - \\
\hline $\mathrm{CRP}, \geqq 2 \mathrm{mg} / \mathrm{L}$ & 0.2 & 2.3 & $0.6-7.9$ & & & \\
\hline Alb, $<3.5 \mathrm{~g} / \mathrm{dL}$ & $<0.01$ & 6.4 & $1.6-25$ & $<0.01$ & 14.5 & $2.2-92$ \\
\hline Lymphocytes, <1000 & 0.55 & 1.3 & $0.6-2.9$ & & & \\
\hline Neutrophils, $\geqq 6000$ & 0.27 & 2.8 & $0.5-17$ & & & \\
\hline $\mathrm{CEA}, \geqq 100 \mathrm{ng} / \mathrm{mL}$ & $<0.01$ & 3.3 & $1.4-8.0$ & - & - & - \\
\hline Peritumoral MCs, high & $<0.01$ & 8.6 & $3.6-20$ & $<0.01$ & 17.3 & $4.8-62$ \\
\hline 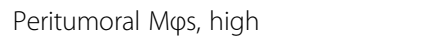 & 0.13 & 2.0 & $0.8-5.0$ & & & \\
\hline Peritumoral mature DCs, high & 0.34 & 1.7 & $0.6-5.3$ & & & \\
\hline
\end{tabular}

Cl confidence interval, CRP C-reactive protein, Alb albumin, CEA carcinoembryonic antigen, MCs mast cells, $M \varphi s$ macrophages, $D C s$ dendritic cells 
received NAC (data not shown). Therefore, determining infiltrating $\mathrm{MC}$ numbers is useful after resection of CRLM even in patients who did not receive NAC.

Consistent with previous studies [24, 29, 32], we found that high numbers of peritumoral MCs were associated with high numbers of microvessels in CRLM. The c-Kit pathway leads to $\mathrm{MC}$ activation and consequent expression of angiogenic cytokines (e.g., VEGF, PDGF, and FGF-2) and degranulation of MCs [19]. Roles of tumorinfiltrating M $\varphi s$ and DCs in some cancers have been reported [39, 40, 45-48]. In this study, peritumoral $M \varphi$ and DC counts were not significant independent predictors of OS in patients with CRLM. Our data, however, must be interpreted in the context of its study design limitations. We recognize that tryptase is not the only MC marker in humans. Therefore, other MC markers such as chymase, histamine, heparin, VEGF, and PDGF$\beta$ should be tested via immunohistochemistry, and the relationship between the number of MCs identified via these markers and OS should be examined.

Ying et al. [49] reported that tumor cells promoted $\mathrm{MC}$ migration in pancreatic ductal adenocarcinoma, and SCF is a previously reported attractant of MCs [18]. Therefore, we need to clarify whether tumor cells produce SCF at metastatic lesions.

The relationship between TIM counts, angiogenesis, and tumor progression suggests that MCs may be a novel therapeutic target in CRLM. c-Kit tyrosine kinase inhibitors (e.g., imatinib and masitinib) may be used to block MC activation and degranulation, and tryptase inhibitors (e.g., gabexate and nafamostat mesylate) may be used to prevent the release of tryptase from MC cells $[18,50-52]$. In the future, such drugs may improve the prognosis of patients with CRLM, particularly those with high $\mathrm{MC}$ infiltration. On the other hand, we did not find any relationship between the number of MCs in primary lesions and CRLM. The results of present study show that the number of MCs in metastatic lesions but not primary lesions is important for predicting the prognosis of CRLM patients and as an indication of therapy.

\section{Conclusions}

The present study shows that the number of infiltrating peritumoral MCs is a significant predictor of unfavorable OS in patients who underwent hepatectomy for CRLM. Further study is required to identify the molecules that attract MCs to peritumoral sites in CRLM.

\section{Abbreviations}

CRC: Colorectal cancer; CRLM: Colorectal liver metastases; DC: Dendritic cell;

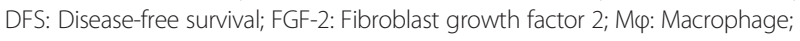
MC: Mast cell; NAC: Neoadjuvant chemotherapy; OS: Overall survival; PDGF: Platelet-derived growth factor; ROC: Receiver operating characteristic; SCF: Stem cell factor; TIM: Tumor-infiltrating mast cell; Treg: Peritumoral regulatory T cells; VEGF: Vascular endothelial growth factor

\section{Competing interests}

The authors declare that they have no competing interests.

\section{Authors' contributions}

SS designed and coordinated the study and drafted the manuscript. YI contributed to study design and drafting of the manuscript. KN performed pathological evaluation. TT performed statistical analyses. TK, RM, RM, KT, MO and KT contributed to study design. IE conceived the study, supervised statistical analyses and helped with manuscript editing. All authors read and approved the final manuscript.

\section{Authors' information}

SS: MD; KN, TK, and RM: MD, PhD, assistant professor; RM and KT: MD, PhD, lecturer; MO: MD, PhD, associate professor; YI, KT, TT and IE: MD, PhD, professor.

\section{Acknowledgments}

This research received no specific grants from any funding agency in the public, commercial or not-for-profit sectors. We thank Dr. Ikuma Kato for his pathological advice and Ms. Harumi Sakurada for her technical support.

\section{Author details}

'Department of Gastroenterological Surgery, Yokohama City University Graduate School of Medicine, 3-9 Fukuura, Kanazawa-ku, Yokohama 236-0004, Japan. ${ }^{2}$ Department of Immunology, Yokohama City University Graduate School of Medicine, 3-9 Fukuura, Kanazawa-ku, Yokohama 236-0004, Japan. ${ }^{3}$ Department of Oncology, Yokohama City University Graduate School of Medicine, 3-9 Fukuura, Kanazawa-ku, Yokohama 236-0004, Japan. ${ }^{4}$ Department of Gastroenterological Surgery, Yokohama City University Medical Center, 4-57 Urafunecho, Minami-ku, Yokohama 232-0024, Japan. ${ }^{5}$ Department of Surgery, Teikyo University Chiba Medical Center, 3426-3 Anesaki, Ichihara 299-0111, Japan.

Received: 17 May 2015 Accepted: 27 October 2015

Published online: 04 November 2015

\section{References}

1. Cunningham D, Atkin W, Lenz HJ, Lynch HT, Minsky B, Nordlinger B, et al. Colorectal cancer. Lancet. 2010;375:1030-47.

2. Howe HL, Wu X, Ries LA, Cokkinides V, Ahmed F, Jemal A, et al. Annual report to the nation on the status of cancer, 1975-2003, featuring cancer among U.S. Hispanic/Latino populations. Cancer. 2006;107:1711-42.

3. Miller G, Biernacki P, Kemeny NE, Gonen M, Downey R, Jarnagin WR, et al. Outcomes after resection of synchronous or metachronous hepatic and pulmonary colorectal metastases. J Am Coll Surg. 2007;205:231-8.

4. Tanaka K, Kumamoto T, Nojiri K, Takeda K, Ichikawa Y, Endo I. Timing of two-stage liver resection during chemotherapy for otherwise unresectable colorectal metastases. World J Surg. 2012;36:1832-41.

5. Tanaka K, Shimada H, Ueda M, Matsuo K, Endo I, Togo S. Role of hepatectomy in treating multiple bilobar colorectal cancer metastases. Surgery. 2008;143:259-70.

6. de Haas RJ, Wicherts DA, Flores E, Azoulay D, Castaing D, Adam R. R1 resection by necessity for colorectal liver metastases: is it still a contraindication to surgery? Ann Surg. 2008;248:626-37.

7. Adam R, Wicherts DA, de Haas RJ, Ciacio O, Lévi F, Paule B, et al. Patients with initially unresectable colorectal liver metastases: is there a possibility of cure? J Clin Oncol. 2009;27:1829-35.

8. Muratore A, Ribero D, Zimmitti G, Mellano A, Langella S, Capussotti L. Resection margin and recurrence-free survival after liver resection of colorectal metastases. Ann Surg Oncol. 2010;17:1324-9.

9. Fridman WH, Pagès F, Sautès-Fridman C, Galon J. The immune contexture in human tumours: impact on clinical outcome. Nat Rev Cancer. 2012;12:298-306.

10. Nakagawa K, Tanaka K, Homma Y, Nojiri K, Kumamoto T, Takeda K, et al. Low infiltration of peritumoral regulatory $T$ cells predicts worse outcome following resection of colorectal liver metastases. Ann Surg Oncol. 2015:22:180-6.

11. Ullah E, Nagi AH, Ashraf M. Angiogenesis and mast cell density as predictors of patient survival in squamous cell carcinoma of lung. J Cancer Res Ther. 2013;9:701-5. 
12. Xia Q, Ding $Y$, Wu XJ, Peng $R Q$, Zhou Q, Zeng J, et al. Mast cells in adjacent normal colon mucosa rather than those in invasive margin are related to progression of colon cancer. Chin J Cancer Res. 2011;23:276-82.

13. Xia Q, Wu XJ, Zhou Q, Jing-Zeng, Hou JH, Pan ZZ, et al. No relationship between the distribution of mast cells and the survival of stage IIIB colon cancer patients. J Transl Med. 2011;9:88.

14. Fakhrjou A, Niroumand-Oscoei SM, Somi MH, Ghojazadeh M, Naghashi S, Samankan S. Prognostic value of tumor-infiltrating mast cells in outcome of patients with esophagus squamous cell carcinoma. J Gastrointest Cancer. 2014;45:48-53.

15. Mohseni MG, Mohammadi A, Heshmat AS, Kosari F, Meysamie AP. The lack of correlation between mast cells and microvessel density with pathologic feature of renal cell carcinoma. Int Urol Nephrol. 2010;42:109-12.

16. Wu X, Zou Y, He X, Yuan R, Chen Y, Lan N, et al. Tumor-infiltrating mast cells in colorectal cancer as a poor prognostic factor. Int J Surg Pathol. 2013;21:111-20.

17. Watanabe S, Miyata Y, Matsuo T, Mochizuki Y, Nishikido M, Hayashi T, et al. High density of tryptase-positive mast cells in patients with renal cell carcinoma on hemodialysis: correlation with expression of stem cell factor and protease activated receptor-2. Hum Pathol. 2012:43:888-97.

18. Huang B, Lei Z, Zhang GM, Li D, Song C, Li B, et al. SCF-mediated mast cell infiltration and activation exacerbate the inflammation and immunosuppression in tumor microenvironment. Blood. 2008;112:1269-79.

19. Hassan S, Kinoshita Y, Kawanami C, Kishi K, Matsushima Y, Ohashi A, et al. Expression of protooncogene c-kit and its ligand stem cell factor (SCF) in gastric carcinoma cell lines. Dig Dis Sci. 1998;43:8-14.

20. Ribatti D, Ranieri G, Basile A, Azzariti A, Paradiso A, Vacca A. Tumor endothelial markers as a target in cancer. Expert Opin Ther Targets. 2012;16:1215-25.

21. Morris DR, Ding Y, Ricks TK, Gullapalli A, Wolfe BL, Trejo J. Protease-activated receptor-2 is essential for factor Vlla and Xa-induced signaling, migration, and invasion of breast cancer cells. Cancer Res. 2006;66:1263307-14.

22. Khazaie K, Blatner NR, Khan MW, Gounari F, Gounaris E, Dennis K, et al. The significant role of mast cells in cancer. Cancer Metastasis Rev. 2011;30:45-60.

23. Ranieri G, Labriola A, Achille G, Florio G, Zito AF, Grammatica L, et al. Microvessel density, mast cell density and thymidine phosphorylase expression in oral squamous carcinoma. Int J Oncol. 2002;21:1317-23.

24. Tomita M, Matsuzaki Y, Edagawa M, Shimizu T, Hara M, Sekiya R, et al. Association of mast cells with tumor angiogenesis in esophageal squamous cell carcinoma. Dis Esophagus. 2001;14:135-8.

25. Mangia A, Malfettone A, Rossi R, Paradiso A, Ranieri G, Simone G, et al. Tissue remodelling in breast cancer: human mast cell tryptase as an initiator of myofibroblast differentiation. Histopathology. 2011;58:1096-106.

26. Raica M, Cimpean AM, Ceausu R, Ribatti D, Gaje P. Interplay between mast cells and lymphatic vessels in different molecular types of breast cancer. Anticancer Res. 2013;33:957-63.

27. Ribatti D, Guidolin D, Marzullo A, Nico B, Annese T, Benagiano V, et al. Mast cells and angiogenesis in gastric carcinoma. Int J Exp Pathol. 2010;91:350-6.

28. Ammendola M, Sacco R, Donato G, Zuccalà V, Russo E, Luposella M, et al. Mast cell positivity to tryptase correlates with metastatic lymph nodes in gastrointestinal cancer patients treated surgically. Oncology. 2013;85:111-6.

29. Gulubova M, Vlaykova T. Prognostic significance of mast cell number and microvascular density for the survival of patients with primary colorectal cancer. J Gastroenterol Hepatol. 2009;24:1265-75.

30. Peng SH, Deng H, Yang JF, Xie PP, Li C, Li H, et al. Significance and relationship between infiltrating inflammatory cell and tumor angiogenesis in hepatocellular carcinoma tissues. World J Gastroenterol. 2005;11:6521-4.

31. Mosca F, Bevilacqua G, Campani D. Inflammatory cells contribute to the generation of an angiogenic phenotype in pancreatic ductal adenocarcinoma. J Clin Pathol. 2004;57:630-6.

32. Tuna B, Yorukoglu K, Unlu M, Mungan MU, Kirkali Z. Association of mast cells with microvessel density in renal cell carcinomas. Eur Urol. 2006;50:530-4.

33. Ibaraki T, Muramatsu M, Takai S. The relationship of tryptase- and chymasepositive mast cells to angiogenesis in stage I non-small cell lung cancer. Eur J Cardiothorac Surg. 2005;28:617-21.

34. Carlini MJ, Dalurzo MC, Lastiri JM, Smith DE, Vasallo BC, Puricelli LI, et al. Mast cell phenotypes and microvessels in non-small cell lung cancer and its prognostic significance. Hum Pathol. 2010;41:697-705.

35. Patruno R, Zizzo N, Zito AF, Catalano V, Valerio P, Pellecchia V, et al. Microvascular density and endothelial area correlate with Ki-67 proliferative rate in the canine non-Hodgkin's lymphoma spontaneous model. Leuk Lymphoma. 2006;47:1138-43.

36. Malfettone A, Silvestris N, Saponaro C, Ranieri G, Russo A, Caruso S, et al. High density of tryptase-positive mast cells in human colorectal cancer: a poor prognostic factor related to protease-activated receptor 2 expression. J Cell Mol Med. 2013;17:1025-37.

37. Tanaka K, Matsuyama R, Takeda K, Matsuo K, Nagano Y, Endo I. Aggressive liver resection including major-vessel resection for colorectal liver metastases. World J Hepatol. 2009;1:79-89.

38. Tanaka K, Hiroshima Y, Nakagawa K, Kumamoto T, Nojiri K, Takeda K, et al. Two-stage hepatectomy with effective perioperative chemotherapy does not induce tumor growth or growth factor expression in liver metastases from colorectal cancer. Surgery. 2013;153:179-88.

39. Mukhtar RA, Moore AP, Tandon VJ, Nseyo O, Twomey P, Adisa CA, et al. Elevated levels of proliferating and recently migrated tumor-associated macrophages confer increased aggressiveness and worse outcomes in breast cancer. Ann Surg Oncol. 2012;19:3979-86.

40. Gao Q, Zhou J, Wang XY, Qiu SJ, Song K, Huang XW, et al. Infiltrating memory/senescent $T$ cell ratio predicts extrahepatic metastasis of hepatocellular carcinoma. Ann Surg Oncol. 2012;19:455-66.

41. Tanigawa N, Amaya H, Matsumura M, Lu C, Kitaoka A, Matsuyama K, et al. Tumor angiogenesis and mode of metastasis in patients with colorectal cancer. Cancer Res. 1997;57:1043-6.

42. Youden WJ. Index for rating diagnostic tests. Cancer. 1950;3:32-5.

43. Nielsen HJ, Hansen U, Christensen IJ, Reimert CM, Brünner N, Moesgaard F, et al. Independent prognostic value of eosinophil and mast cell infiltration in colorectal cancer tissue. J Pathol. 1999;189:487-95.

44. Tan SY, Fan Y, Luo HS, Shen ZX, Guo Y, Zhao LJ. Prognostic significance of cell infiltrations of immunosurveillance in colorectal cancer. World J Gastroenterol. 2005;11:1210-4.

45. Zhang $W$, Zhu X-D, Sun H-C, Xiong YQ, Zhuang PY, Xu HX, et al. Depletion of tumor-associated macrophages enhances the effect of sorafenib in metastatic liver cancer models by antimetastatic and antiangiogenic effects. Clin Cancer Res. 2010;16:3420-30.

46. Hao NB, Lü MH, Fan YH, Cao YL, Zhang ZR, Yang SM. Macrophages in tumor microenvironments and the progression of tumors. Clin Dev Immunol. 2012. doi:10.1155/2012/9480982012.

47. Miyagawa S, Soeda J, Takagi S, Miwa S, Ichikawa E, Noike T. Prognostic significance of mature dendritic cells and factors associated with their accumulation in metastatic liver tumors from colorectal cancer. Hum Pathol. 2004;35:1392-6.

48. Gri G, Piconese S, Frossi B, Manfroi V, Merluzzi S, Tripodo C, et al. CD4 ${ }^{+}$CD25 $5^{+}$ regulatory $T$ cells suppress mast cell degranulation and allergic responses through OX40-OX40L interaction. Immunity. 2008;29:771-81.

49. Ma Y, Hwang RF, Logsdon CD, Ullrich SE. Dynamic mast cell-stromal cell interactions promote growth of pancreatic cancer. Cancer Res. 2013;73:3927-37.

50. Erba F, Fiorucci L, Pascarella S, Menegatti E, Ascenzi P, Ascoli F. Selective inhibition of human mast cell tryptase by gabexate mesylate, an antiproteinase drug. Biochem Pharmacol. 2001;61:271-6.

51. Mori S, Itoh Y, Shinohata R, Sendo T, Oishi R, Nishibori M. Nafamostat mesilate is an extremely potent inhibitor of human tryptase. J Pharmacol Sci. 2003;92:420-3.

52. Bai Y, Bandara G, Ching Chan E, Maric I, Simakova O, Bandara SN, et al. Targeting the KIT activating switch control pocket: a novel mechanism to inhibit neoplastic mast cell proliferation and mast cell activation. Leukemia. 2013;27:278-85. 